\title{
Induced plant responses to microbes and insects
}

\section{Corné M. J. Pieterse ${ }^{1 *}$, Erik H. Poelman ${ }^{2}$, Saskia C. M. Van Wees ${ }^{1}$ and Marcel Dicke ${ }^{2}$}

1 Plant-Microbe Interactions, Department of Biology, Faculty of Science, Utrecht University, Utrecht, Netherlands

${ }^{2}$ Laboratory of Entomology, Department of Plant Science, Wageningen University, Wageningen, Netherlands

*Correspondence: c.m.j.pieterse@uu.nl

Edited by:

Mary B. Mudgett, Stanford University, USA

Keywords: induced systemic resistance, systemic acquired resistance, insect-induced defense, priming, plant defense signaling, volatile organic compounds, microbiome, beneficial microbes

Plants play a key role in the sustainability of life on earth. They fix the solar energy that drives nearly all living processes. As a result, plants are members of complex communities and interact both with antagonists and beneficial organisms. To defend themselves against harmful pathogens and insects, plants have evolved a sophisticated immune system to perceive alien organisms, and to translate this perception into defense. The plant immune system is based on a surprisingly complex defense signaling network that is highly flexible in its capacity to recognize and respond to the invader encountered. Plant hormones and volatile organic compounds emerged as important signaling molecules in local and systemic induced defense responses to pathogen or insect attack.

Beneficial relationships between plants and microorganisms are frequent in nature as well, improving plant growth or helping the plant to overcome biotic or abiotic stress. Beneficial associations include root-colonizing microbes, such as plant growthpromoting rhizobacteria and fungi, and mycorrhizal fungi that form a symbiosis with $\sim 80 \%$ of all plant species. These ecologically and agriculturally important beneficial associations are based on the exchange of resources between the plant and the mutualist. Each gram of soil contains billions of microbes. However, the microbial community on plant roots is very different from that in bulk soil. Hence, plants are able to recruit specific microbes from the soil to their roots. The establishment of beneficial associations requires mutual recognition and a high degree of coordination of plant and microbial responses through a continuous molecular dialog between the plant and the beneficial. Because beneficial microbes are recognized as alien organisms, active interference with the plant immune system is fundamental for the establishment of intimate mutualistic relationships.

An important question in plant defense signaling research is: how do plants integrate signals induced by pathogens, insect herbivores and beneficial microbes into an adaptive response that maximizes both profitable and protective functions? Molecular and genomic tools are now being used to uncover the complexity of the induced signaling networks that have evolved during the arms races between plants and the organisms with which they intimately interact. To understand the functioning of this complex signaling network in nature, molecular biologists and ecologists have joined forces to place molecular mechanisms of induced plant defenses in an ecological perspective. Exciting new discoveries have greatly advanced our understanding of how the co-evolutionary arms race between plants and its social network has shaped the plant immune system into a sophisticated defensive shield capable of warding off the majority of harmful organisms in its environment. Tremendous progress has also been made in the understanding of how plants respond to and benefit from mutualistic soil-borne microbes to maximize growth and survival. With 31 original contributions, this Research Topic provides a snapshot of the current state of the art of the field of induced plant responses to microbial pathogens, insect herbivores, and beneficial root-associated microbes, with a special focus on the translation of molecular mechanisms to ecology and vice versa.

In this Research Topic, a nice mix of Mini Reviews, Reviews, Original Research Articles, and Opinion Articles provide up-todate information on diverse aspects of the plant immune system and how it functions against microbial pathogens. Newman et al. (2013) provide an update on the wide variety of microbeassociated molecular patterns (MAMPS) that to date have been characterized in bacterial, fungal and oomycetal pathogens. Locally triggered immune responses are often associated with systemic acquired resistance (SAR). This requires long-distance communication and signal amplification in distal plant parts. In recent years, many candidate molecules that function as systemically transported signals have been characterized (reviewed by Shah and Zeier, 2013). Other aspects of SAR, such as detailed insight in transcriptional reprogramming during SAR (Gruner et al., 2013), the role of the NPR1 regulatory NIMIN proteins in SAR (Hermann et al., 2013), and the effect of abiotic stress on the expression of SAR (Pye et al., 2013) are discussed in this Research Topic and provide interesting new insights into the field of SAR research. Plant hormones emerged as important regulators of local and systemic induced defense responses. Besides the classic defense-related hormones salicylic acid, jasmonic acid and ethylene, nitric oxide emerged as an important regulatory signal as well. In their Mini Review, Mur et al. (2013) integrate nitric oxide into the network of hormone-regulated immune responses.

More specific topics on plant-pathogen interactions are addressed by Zhang et al. (2013), who report on the role of the Sec61 ER protein transporting pore in susceptibility to powdery mildew. Singh and Zimmerli (2013) provide a nice review on the role of lectin receptor kinases in plant immunity. Yadeta and Thomma (2013) zoom in on the xylem as site of action when it comes to plant defense against vascular pathogens. Davidsson et al. (2013) provide insight into the state-of-theart of pathogenicity of soft rot pectobacteria and the defensive machinery of plants to protect themselves against this group of pathogens. Cereal pathogens have major impacts on future food security. Ballini et al. (2013) and Balmer et al. (2013) describe how modern technology such as genetical genomics and metabolomics 
can help to investigate these scientifically and societally challenging host-pathogen interactions. On a more applied note, Abdul Latif et al. (2013) and Reglinski et al. (2013) describe how modeling approaches and fundamental knowledge on induced resistance can be used to develop control strategies in practice, such as to fight bacterial canker of kiwifruit.

A major topic in plant-insect interactions is the aspect of above-belowground interactions between plants, insects and other organisms. Wondafrash et al. (2013) review the field of systemic induced defense responses triggered by root parasitic nematodes and their effects against herbivorous insects on foliar tissues. In their original research articles, Paudel et al. (2013) and Schweizer et al. (2013) provide novel insights into the role of different transcription factors and the cellular redox status in the regulation of induced defense against caterpillar herbivory. Sapsucking insects have a completely different mode of action. De Vos and Vandoorn (2013) review current knowledge on resistance to this group of insects in modern-day agriculture.

Plant volatiles emerged as important signals in the communication between plants, insect herbivores, and their enemies. In this Research Topic a number of contributions address the role of volatile organic compounds in the communication of the plant's social network. Von Mérey et al. (2013) describe the role of herbivore-induced plant volatiles in the attraction and feeding behavior of a caterpillar herbivore. Scala et al. (2013) investigated the effect of a common herbivore-induced plant volatile on a bacterial plant pathogen. Rodriguez-Saona et al. (2013) investigated the role of jasmonate-mediated induction of plant volatiles on multi-trophic level interactions in American cranberry, while Niinemets et al. (2013) addressed the question how volatile emission patterns induced by biotic stresses relate to the degree of damage. After release into the atmosphere, the plant no longer controls the action of its produced volatiles. In their review "Where do herbivore-induced plant volatiles go" Holopainen and Blande (2013) summarize the potential ecological and atmospheric processes that involve the reaction products of plant volatiles that are formed in the atmosphere upon release by the plant.

An emerging theme in the field of plant-microbe interactions is the importance of beneficial microbes in plant health. Bakker et al. (2013) reviewed the field of root microbiomics and highlights the role of root-associated beneficial microbes in plant growth and protection. Studies by Carvalhais et al. (2013), Hol et al. (2013) and Yi et al. (2013) provide additional insight into the roles of plant growth-promoting rhizobacteria in plant health, either as stimulants of the plant's immune system or through optimizing the root microbial ecology. Paszkowski and Gutjahr (2013) provide an excellent review on the mechanisms by which arbuscular mycorrhizal fungi shape the architecture of plants roots, which is essential for optimal acquisition of mineral nutrients and water from the soil. Furthermore, novel insights into mechanisms by which plant growth-promoting fungi, such as Piriformospora indica and Trichoderma spp., interact with the plant immune system or antagonize pathogens in the soil are provided by contributions of Martinez-Medina et al. (2013), Rafiqi et al. (2013) and Studholme et al. (2013).
With this Research Topic we aimed to provide a platform for scientists who liked to share their understanding of how induced plant responses shape the plant's social network. The excellent contributions are a demonstration of a highly active research community in plant science. Together they provide a detailed understanding of the intrinsic capacity of plants to simultaneously accommodate mutualists and ward off enemies to maximize both growth-stimulating and protective functions.

\section{ACKNOWLEDGMENTS}

Research in the laboratories of the Topic Editors is supported by ERC Advanced grant 269072 (Corné M. J. Pieterse), NWOVIDI grant 11281 (Saskia C. M. Van Wees), NWO-VENI grant 863.10.012 (Erik H. Poelman), and the European Science Foundation EUROCORES Programme EuroVOL (Marcel Dicke, Erik H. Poelman, Corné M. J. Pieterse).

\section{REFERENCES}

Abdul Latif, N. S., Wake, G. C., Reglinski, T., Elmer, P.a.H., and Taylor, J. T. (2013). Modeling induced resistance to plant disease using a dynamical systems approach. Front. Plant Sci. 4:19. doi: 10.3389/fpls.2013.00019

Bakker, P. A. H. M., Berendsen, R. L., Doornbos, R. F., Wintermans, P. C. A., and Pieterse, C. M. J. (2013). The rhizosphere revisited: root microbiomics. Front. Plant Sci. 4:165. doi: 10.3389/fpls.2013.00165

Ballini, E., Lauter, N., and Wise, R. (2013). Prospects for advancing defense to cereal rusts through genetical genomics. Front. Plant Sci. 4:117. doi: 10.3389/fpls.2013.00117

Balmer, D., Flors, V., Glauser, G., and Mauch-Mani, B. (2013). Metabolomics of cereals under biotic stress: current knowledge and techniques. Front. Plant Sci. 4:82. doi: 10.3389/fpls.2013.00082

Carvalhais, L. C., Muzzi, F., Tan, C.-H., Schenk, P. M., and Choo, J. H. (2013). Plant growth in Arabidopsis is assisted by compost soil-derived microbial communities. Front. Plant Sci. 4:235. doi: 10.3389/fpls.2013.00235

Davidsson, P. R., Kariola, T., Niemi, O., and Palva, E. T. (2013). Pathogenicity of and plant immunity to soft rot pectobacteria. Front. Plant Sci. 4:191. doi: 10.3389/fpls.2013.00191

De Vos, M., and Vandoorn, A. (2013). Resistance to sap-sucking insects in modernday agriculture. Front. Plant Sci. 4:222. doi: 10.3389/fpls.2013.00222

Gruner, K., Griebel, T., Návarová, H., Attaran, E., and Zeier, J. (2013). Reprogramming of plants during systemic acquired resistance. Front. Plant Sci. 4:252. doi: 10.3389/fpls.2013.00252

Hermann, M., Maier, F., Masroor, A., Hirth, S., Pfitzner, A. J. P., and Pfitzner, U. M. (2013). The Arabidopsis NIMIN proteins affect NPR1 differentially. Front. Plant Sci. 4:88. doi: 10.3389/fpls.2013.00088

Hol, W. H. G., Bezemer, T. M., and Biere, A. (2013). Getting the ecology into interactions between plants and the plant growth-promoting bacterium Pseudomonas fluorescens. Front. Plant Sci. 4:81. doi: 10.3389/fpls.2013.00081

Holopainen, J. K., and Blande, J. D. (2013). Where do herbivore-induced plant volatiles go? Front. Plant Sci. 4:185. doi: 10.3389/fpls.2013.00185

Martinez-Medina, A., Fernandez, I., Sánchez-Guzmán, M. J., Jung, S. C., Pascual, J. A., and Pozo, M. J. (2013). Deciphering the hormonal signalling network behind the systemic resistance induced by Trichoderma harzianum in tomato. Front. Plant Sci. 4:206. doi: 10.3389/fpls.2013.00206

Mur, L.a.J., Prats, E., Pierre, S., Hall, M. A., and Hebelstrup, K. H. (2013). Integrating nitric oxide into salicylic acid and jasmonic acid/ ethylene plant defense pathways. Front. Plant Sci. 4:215. doi: 10.3389/fpls.2013.00215

Newman, M.-A., Sundelin, T., Nielsen, J. T., and Erbs, G. (2013). MAMP (microbeassociated molecular pattern) triggered immunity in plants. Front. Plant Sci. 4:139. doi: 10.3389/fpls.2013.00139

Niinemets, U., Kännaste, A., and Copolovici, L. (2013). Quantitative patterns between plant volatile emissions induced by biotic stresses and the degree of damage Front. Plant Sci. 4:262. doi: 10.3389/fpls.2013.00262

Paszkowski, U., and Gutjahr, C. (2013). Multiple control levels of root system remodeling in arbuscular mycorrhizal symbiosis. Front. Plant Sci. 4:204. doi: $10.3389 /$ fpls.2013.00204 
Paudel, J., Copley, T., Amirizian, A., Prado, A., and Bede, J. C. (2013). Arabidopsis redox status in response to caterpillar herbivory. Front. Plant Sci. 4:113. doi: 10.3389/fpls.2013.00113

Pye, M. F., Hakuno, F., Macdonald, J. D., and Bostock, R. M. (2013). Induced resistance in tomato by SAR activators during predisposing salinity stress. Front. Plant Sci. 4:116. doi: 10.3389/fpls.2013.00116

Rafiqi, M., Jelonek, L., Akum, N. F., Zhang, F., and Kogel, K.-H. (2013). Effector candidates in the secretome of Piriformospora indica, a ubiquitous plantassociated fungus. Front. Plant Sci. 4:228. doi: 10.3389/fpls.2013.00228

Reglinski, R., Vanneste, J. L., Wurms, K., Gould, E., Spinelli, F., and Rikkerink, E. (2013). Using fundamental knowledge of induced resistance to develop control strategies for bacterial canker of kiwifruit caused by Pseudomonas syringae pv. actinidiae. Front. Plant Sci. 4:24. doi: 10.3389/fpls.2013.00024

Rodriguez-Saona, C. R., Polashock, J., and Malo, E. A. (2013). Jasmonatemediated induced volatiles in the American cranberry, Vaccinium macrocarpon: from gene expression to organismal interactions. Front. Plant Sci. 4:115. doi: 10.3389/fpls.2013.00115

Scala, A., Mirabella, R., Mugo, C., Matsui, K., Haring, M. A., and Schuurink, R. C. (2013). E-2-hexenal promotes susceptibility to Pseudomonas syringae by activating jasmonic acid pathways in Arabidopsis. Front. Plant Sci. 4:74. doi: 10.3389/fpls.2013.00074

Schweizer, F., Bodenhausen, N., Lassueur, S., Masclaux, F. G., and Reymond, P. (2013). Differential contribution of transcription factors to Arabidopsis thaliana defense against Spodoptera littoralis. Front. Plant Sci. 4:13. doi: $10.3389 /$ fpls. 2013.00013

Shah, J., and Zeier, J. (2013). Long-distance communication and signal amplification in systemic acquired resistance. Front. Plant Sci. 4:30. doi: 10.3389/fpls.2013.00030

Singh, P., and Zimmerli, L. (2013). Lectin receptor kinases in plant innate immunity. Front. Plant Sci. 4:124. doi: 10.3389/fpls.2013.00124

Studholme, D. J., Harris, B., Le Cocq, K., Winsbury, R., Perera, V., Ryder, L., et al. (2013). Investigating the beneficial traits of Trichoderma hamatum GD12 for sustainable agriculture-insights from genomics. Front. Plant Sci. 4:258. doi: $10.3389 /$ fpls. 2013.00258
Von Mérey, G. E., Veyrat, N., D'alessandro, M., and Turlings, T. (2013). Herbivore-induced maize leaf volatiles affect attraction and feeding behavior of Spodoptera littoralis caterpillars. Front. Plant Sci. 4:209. doi: 10.3389/fpls.2013. 00209

Wondafrash, M., Van Dam, N. M., and Tytgat, T. O. G. (2013). Plant systemic induced responses mediate interactions between root parasitic nematodes and aboveground herbivorous insects. Front. Plant Sci. 4:87. doi: 10.3389/fpls.2013.00087

Yadeta, K. A., and Thomma, B. P. H. J. (2013). The xylem as battleground for plant hosts and vascular wilt pathogens. Front. Plant Sci. 4:97. doi: 10.3389/fpls.2013.00097

Yi, H.-S., Yang, J. W., and Ryu, C.-M. (2013). ISR meets SAR outside: additive action of the endophyte Bacillus pumilus INR7 and the chemical inducer, benzothiadiazole, on induced resistance against bacterial spot in field-grown pepper. Front. Plant Sci. 4:122. doi: 10.3389/fpls.2013.00122

Zhang, W.-J., Hanisch, S., Kwaaitaal, M., Pedersen, C., and Thordal-Christensen, H. (2013). A component of the Sec61 ER protein transporting pore is required for plant susceptibility to powdery mildew. Front. Plant Sci. 4:127. doi: $10.3389 /$ fpls.2013.00127

Received: 23 October 2013; accepted: 03 November 2013; published online: 21 November 2013.

Citation: Pieterse CMJ, Poelman EH, Van Wees SCM and Dicke M (2013) Induced plant responses to microbes and insects. Front. Plant Sci. 4:475. doi: 10.3389/fpls. 2013.00475

This article was submitted to Plant-Microbe Interaction, a section of the journal Frontiers in Plant Science.

Copyright (c) 2013 Pieterse, Poelman, Van Wees and Dicke. This is an open-access article distributed under the terms of the Creative Commons Attribution License (CC BY). The use, distribution or reproduction in other forums is permitted, provided the original author(s) or licensor are credited and that the original publication in this journal is cited, in accordance with accepted academic practice. No use, distribution or reproduction is permitted which does not comply with these terms. 